\title{
Relevance of nearness or proximity of lines in the perception of objects
}

\author{
RENATE R. MAI-DALTON and DAVID A. COWAN \\ University of Kansas, Lawrence, Kansas 66045 \\ and \\ RICHARD J. STANEK \\ Southern Oregon State College, Ashland, Oregon 97520
}

\begin{abstract}
A study by Egon Brunswik and Joe Kamiya was partially replicated to test if "nearness" of parallel lines for mechanical units is closer than for open passages. In contrast to Brunswik and Kamiya's study, a representative sample of actual life situations was taken and the distances between parallel lines on five enlarged photographs were measured. It was found that the mean distance of parallel lines for mechanical units was smaller than the mean distance of parallel lines for passages. Brunswik and Kamiya's original hypothesis was supported: The organism might learn to discriminate between objects and open spaces because the mean distances between boundaries of objects are smaller than those of open spaces.
\end{abstract}

Orthodox Gestalt theory asserts that visual perception of proximity, similarity, symmetry, good continuation, and closure depends on dynamic processes in the brainfield. According to this view, any change in the form or organization of stimuli is due to a redistribution of dynamic forces within the brain-field. These forces consist of "physical Gestalten" that were built into the organism before any learning had taken place (Gibson, 1969).

In opposition to this view stand findings of Egon Brunswik and Joe Kamiya, who conducted a study to support their hypothesis that nearness or proximity of lines serves as a guide to life-relevant physical properties and is learned by the organism in its interaction with the environment (Brunswik \& Kamiya, 1953).

The significance of properties such as these, inherent in the stimulus field, are being included in current perceptual studies but may not be receiving adequate attention. Appelle (1980) has shown that the perceptual process of selecting a figure from an environment is generally performed more rapidly and with significantly less variability for horizontal-vertical (H-V) figures than for oblique figures. In part, these findings may depend on the reinforcement effect suggested by Brunswik and Kamiya (1953) in learning to interact with an environment increasingly occupied with H-V objects. Explanations for performance levels, such as Appelle's search time for target figures, may well depend on these reinforcing effects.

Brunswik and Kamiya (1953) examined seven enlarged photographs (approximately $4 \times 5$ in.) of a motion picture as to their distance between parallel lines for mechanical units (MU) and passages (P). MU were defined as "all separations in which both lines of the pair represent mechanical boundaries of one and the same mechanically coherent object" (Brunswik \& Kamiya, 1953, p. 26).
The category of $\mathbf{P}$ was subsumed under "separations representing holes, gaps, passages, or spaces between mechanical units; these separations traverse over a depth or recession, with the background fill overlapped on both sides by other objects" (Brunswik \& Kamiya, 1953, p. 26).

The experimenters found that the mean distance between $334 \mathrm{MU}$ was $1.2 \mathrm{~mm}$, compared with a mean distance of $2.8 \mathrm{~mm}$ between $171 \mathrm{P}$. The range for both measurements was $64 \mathrm{~mm}$; the point-biserial correlation was .34.

Brunswik and Kamiya concluded that "the frequently emphasized perceptual organization effect of proximity ... may thus well be rooted in a generalized probability learning of its overall ecological validity in the naturalcultural universe to which we are habitually exposed, rather than in an 'autochtonous' gestalt dynamics of the brain-field" (1953, p. 32).

In view of Brunswik's (1956) repeated emphasis on representational design of experiments, it could be argued that the settings in motion pictures might not be analogous to actual life situations. The present study has taken this criticism into account and used enlarged photographs that were taken at randomly selected times in order to evaluate proximity of parallel lines of MU and $\mathbf{P}$.

\section{METHOD}

The first author was the subject of this study. The materials consisted of a Petri camera and 35-mm Ektachrome film.

In order to obtain photographs during waking hours, a period between 7:30 a.m. and 10:00 p.m. was divided into 15-min sections. At eight randomly determined times (a.m.-9:00, 9:30, $10: 30$; p.m. $-3: 45,4: 15,5: 45,6: 15$, and $7: 00$ ), the subject took a picture of whatever she happened to look at when an alarm went off. The photographs were developed and the five 


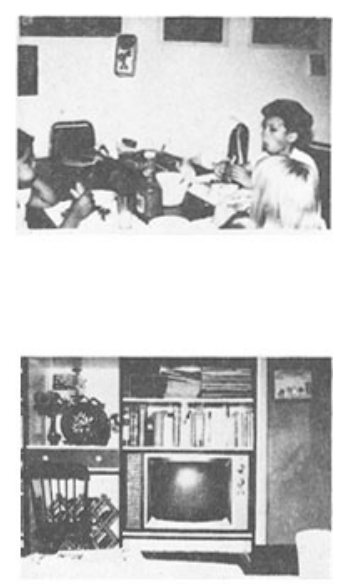

Figure 1.

sharpest ones were selected for $8 \times 10$ in. enlargements and subsequent analysis.

For this study, Brunswik and Kamiya's (1953) definitions for MU and P were retained.

\section{RESULTS}

The five enlargements (Figure 1) yielded a total of 208 observations of parallel lines of MU and P. The measurements resulted in $154 \mathrm{MU}$ observations, but only $54 \mathrm{P}$ within parallel lines were found. MU had a weighted mean of $7.3 \mathrm{~mm}$, compared with the weighted mean of $17.4 \mathrm{~mm}$ for $\mathrm{P}(\mathrm{t}=4.18, \mathrm{p}=.01)$. The range was $149 \mathrm{~mm}$; the point-biserial correlation coefficient was $r=.28$ $\left(\mathrm{r}^{2}=.06, \mathrm{p}=.010\right)$.

Table 1

Number of Observations, Means, and Range for Each of Five Photographs

\begin{tabular}{lrrrrr}
\hline & \multicolumn{5}{c}{ Picture } \\
\cline { 2 - 6 } Observation & 1 & 2 & 3 & 4 & 5 \\
\hline & \multicolumn{5}{c}{ Number of Observations } \\
Mechanical Units & 39 & 25 & 20 & 14 & 56 \\
Passages & 18 & 14 & 4 & 6 & 12 \\
& \multicolumn{5}{c}{ Mean (in Millimeters) } \\
Mechanical Units & 5.8 & 7.6 & 15.1 & 14.1 & 3.8 \\
Passages & 17.3 & 6.8 & 19.6 & 34.3 & 20.6 \\
& \multicolumn{5}{c}{ Range (in Millimeters) } \\
Mechanical Units & 53.0 & 38.5 & 30.0 & 52.0 & 15.0 \\
Passages & 48.5 & 28.0 & 64.0 & 148.0 & 90.0 \\
\hline
\end{tabular}

Table 1 shows the $\mathrm{N}$ of observations, means, and the range for $\mathrm{MU}$ and $\mathrm{P}$ in each photograph.

\section{DISCUSSION}

The results acknowledged Brunswik and Kamiya's (1953) earlier observations that the mean distance between parallel lines of $\mathrm{MU}$ is smaller than the mean distance between parallel lines of $P$. The smaller mean of $P$ in Picture 2, in contrast to the larger means of $\mathbf{P}$ in the remaining four pictures, was probably the result of the content of this particular photograph. It contains one large building from which most of the $P$ observations were taken. However, considering that this photograph was the only one taken outside a residence, this finding might encourage further study of outdoor pictures in other experiments.

The range of the measurements in this study is compatible with Brunswik and Kamiya's (1953) findings when the larger size of the photographs is taken into account. The point-biserial correlation coefficient is also similar.

In agreement with Brunswik and Kamiya's (1953) findings, this study resulted in considerably more measurements for MU than for P. It seems reasonable to assume that man-made objects are built in forms that generate parallel lines to which the organism learns to adapt.

Although this analysis does not show conclusively that the organism learns to adjust to the environment by repeated spatial approximation, the possibility that this is the case cannot be excluded. Previous research by Beardslee and Wertheimer (1958), indeed, has shown that nearness of two constituent items in pairs of two dots or parallel lines were interpreted by subjects as a perceptual unity. Our and Brunswik's (1956) hypothesis could be disproved if an environment could be found or constructed that does not exhibit the obtained relationship between $\mathrm{MU}$ and $\mathrm{P}$ and organisms would fail to adapt to it after repeated exposures to this ecology. 


\section{REFERENCES}

APPELLE, S. Figure embeddedness as a function of the orientation of embedding-field contours. Perception, 1980, 9, 627-632.

BeARDSlee, D. C., \& Wertheimer, M. Readings in perception. Princeton, N.J: Van Nostrand, 1958.

BRUNSWIK, E. Perception and the representative design of psychological experiments. Berkeley: University of California Press, 1956.

Brunswik, E., \& Kamiya, J. Ecological cue-validity of "proximity" and other Gestalt factors. American Journal of Psychology, 1953, 66, 20-32.

Gibson, E. J. Principles of perceptual learning and development. New York: Appleton-Century-Crofts, 1969.

(Received for publication May 7, 1982.) 